Int. J. Electrochem. Sci., 14 (2019) 9527 - 9536

\title{
Electrochemical Behavior of 3,4-ethylenedioxythiophene as an Anti-overcharge Additive for Lithium-ion Batteries
}

\author{
Sai Wang ${ }^{1}$, Jianxiong Liu ${ }^{1}$, Xiaohua Yu ${ }^{1}$, , Jiaming Liu ${ }^{3}$, JuRong ${ }^{1}$, Chengyi Zhu ${ }^{1}$, Qiang Wang ${ }^{1}$, \\ Zhentao Yuan ${ }^{1}$, Yannan Zhang ${ }^{2, *}$ \\ ${ }^{1}$ Faculty of Materials Science and Engineering, Kunming University of Science and Technology, \\ Kunming 650093, China \\ ${ }^{2}$ National and Local Joint Engineering Laboratory for Lithium-ion Batteries and Materials Preparation \\ Technology, Key Laboratory of Advanced Battery Materials of Yunnan Province, Faculty of \\ Metallurgical and Energy Engineering, Kunming University of Science and Technology, Kunming \\ 650093, China \\ ${ }^{3}$ School of Metallurgy Engineering, Jiangxi University of Science and Technology, Ganzhou 341000, \\ China \\ *E-mail: xiaohua_y@163.com (Xiaohua Yu), zyn_legolas@163.com (Yannan Zhang)
}

doi: $10.20964 / 2019.10 .36$

Received: 5 June 2019 / Accepted: 28 July 2019 / Published: 30 August 2019

The overcharge protection performance of $\mathrm{LiNi}_{0.8} \mathrm{Co}_{0.1} \mathrm{Mn}_{0.1} \mathrm{O}_{2}$ as the positive electrode materials for the lithium-ion batteries is significantly enhanced by adding 3,4-ethylenedioxythiophene (EDOT) into the electrolyte. The effect of anti-overcharge on $\mathrm{LiNi}{ }_{.} \mathrm{Co}\left({ }_{1} \mathrm{Mn}_{0.1} \mathrm{O}_{2}\right.$ electrodes are analyzed by microelectrode linear scan voltammetry measurement, electrochemical impedance measurement, constant current charge/discharge and overcharged tests. The cycled electrodes are also tested by scanning electron microscopy (SEM) and X-ray diffraction (XRD) analysis. The results show that the EDOT additive can react with the base electrolyte and easily form a polymer layer on the surface of LiNi ${ }_{0.8} \mathrm{Co}_{0.1} \mathrm{Mn}_{0.1} \mathrm{O}_{2}$ electrodes at a stable platform of $4.4 \mathrm{~V}\left(\mathrm{vs} \mathrm{Li} / \mathrm{Li}^{+}\right)$. The time for the voltage rising to the overcharge state is apparently delayed from $25 \mathrm{~h}$ to $58 \mathrm{~h}$. After 100 cycles at $0.5 \mathrm{C}$ rate, the capacity retention rate of the half-cell is increased from $80.1 \%$ to $93.4 \%$ after adding the EDOT additive. The results demonstrate that this promising anti-overcharged and cyclic performance are attributed to the protective film generated by EDOT which may enhance the interfacial stability of LiNio. ${ }_{8} \mathrm{Co}_{0.1} \mathrm{Mn}_{0.1} \mathrm{O}_{2} /$ electrolyte.

Keywords:3,4-ethoxylenedioxythiophene, electrolyte additive, overcharge, $\mathrm{LiNi}_{0.8} \mathrm{Co}_{0.1} \mathrm{Mn}_{0.1} \mathrm{O}_{2}$, lithium-ion batteries 
(C) 2019 The Authors. Published by ESG (www.electrochemsci.org). This article is an open access article distributed under the terms and conditions of the Creative Commons Attribution license (http://creativecommons.org/licenses/by/4.0/). 